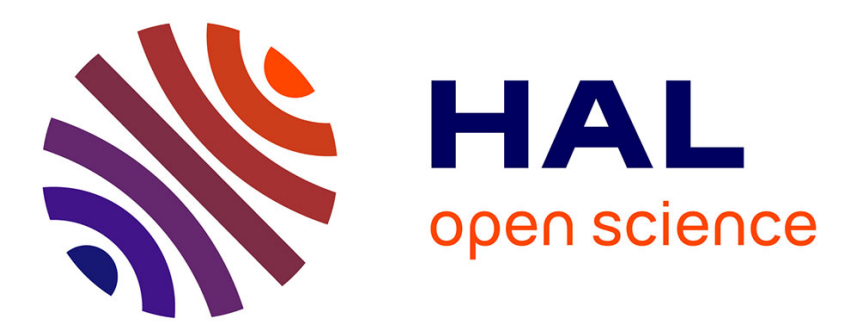

\title{
Experimental apparatus for studying heat transfer in externally heated rotary kilns
}

Phahath Thammavong, Marie Debacq, Stéphane Vitu, Marc Dupoizat

\section{To cite this version:}

Phahath Thammavong, Marie Debacq, Stéphane Vitu, Marc Dupoizat. Experimental apparatus for studying heat transfer in externally heated rotary kilns. Chemical Engineering and Technology, 2011, 34 (5), pp.707-717. 10.1002/ceat.201000391 . hal-00984180

\section{HAL Id: hal-00984180 \\ https://hal.science/hal-00984180}

Submitted on 4 Apr 2017

HAL is a multi-disciplinary open access archive for the deposit and dissemination of scientific research documents, whether they are published or not. The documents may come from teaching and research institutions in France or abroad, or from public or private research centers.
L'archive ouverte pluridisciplinaire HAL, est destinée au dépôt et à la diffusion de documents scientifiques de niveau recherche, publiés ou non, émanant des établissements d'enseignement et de recherche français ou étrangers, des laboratoires publics ou privés.

\section{(ㅇ)(1) $\$$}

Distributed under a Creative Commons Attribution - NonCommercial - NoDerivatives| 4.0 


\title{
Experimental apparatus for studying heat transfer in externally heated rotary kilns
}

\author{
Phahath THAMMAVONG ${ }^{1}$, Marie DEBACQ ${ }^{1}$, Stéphane VITU ${ }^{1}$ and Marc DUPOIZAT ${ }^{2}$ \\ 1 Laboratoire de Génie des Procédés pour 1'Environnement, l'Energie et la Santé (EA21), \\ Conservatoire National des Arts et Métiers, Paris, France. \\ ${ }^{2}$ Areva NC, Business Unit Chimie, Pierrelatte, France.
}

DOI: $10.1002 /$ ceat.201000391

Chemical Engineering and Technology 34-5 (2011) 707-717

Correspondence: Dr. M. Debacq (marie.debacq@cnam.fr), Laboratoire de Génie des Procédés pour l'Environnement, l'Energie et la Santé, Conservatoire National des Arts et Métiers, case courrier 302, 2 rue Conté, 75003 Paris, France.

\begin{abstract}
Rotary kilns are widely used in several branches of the chemical industry. In order to control the temperature of the solid and the gas flowing through the kiln, it is important to understand the heat exchange phenomena that occur.

This article describes the design and construction of a novel experimental device to study heat exchange in rotary kilns. The device, which comprises a rotary kiln equipped with an external electrical heating system, enables the study of the influence of various parameters such as the solid flow rate, the kiln inclination angle, the rotational speed, or the presence of lifters on heat exchange and in particular on the heat exchange coefficient between the solid and the wall.

Preliminary experimental results concerning the influence of the solid flow rate and the rotational speed on the solid/wall heat exchange coefficient are here presented.
\end{abstract}

Keywords: Rotary kiln, rotary cylinder, lifter, flight, gas/solid reactor, heat transfer, heat transfer coefficient, pilot plant, experimentation 


\section{Introduction and background to the problem}

For over a century [1], rotary kilns have been widely used in the inorganic chemistry industry. They are a key element in the production processes of cement, lime and pigments (titanium dioxide calcination) and in extractive metallurgy for the reduction of ore [2]. Rotary kilns are well suited for the pyrolysis of solid waste [3,4], and are also used to convert uranium fluoride into uranium dioxide for the manufacture of nuclear fuel.

Natural uranium cannot be processed directly because its content in isotope 235, the only fissionable isotope, is too low. To enrich the mineral, the uranium is therefore first converted into uranium hexafluoride $\left(\mathrm{UF}_{6}\right)$. Enrichment in isotope 235 is carried out in the gas phase, either by gaseous diffusion or by centrifugation. The depleted uranium is then converted into a chemically stable and insoluble oxide, $\mathrm{U}_{3} \mathrm{O}_{8}$, and stored. The enriched uranium is converted into solid $\mathrm{UO}_{2}$ used to produce the solid fuel for nuclear power plants [5]. Both processes are conducted in conversion kilns, which comprise a hydrolysis reactor and a rotary kiln fitted with lifters. Rotary conversion kilns are externally heated by resistors located close to the outside wall of the rotating cylinder.

Various studies have been carried out on conversion kilns in an attempt to simulate their hydrodynamic, chemical and thermal behavior [5]. In this type of kiln, hydrodynamic, thermal and chemical modelling processes are closely linked, as it is clear that the temperature profiles of the solid and the gas in the kiln directly influence the chemical reaction kinetics that occur. In order to correctly model the operation of the kiln it is essential to be able to calculate precisely the temperature of the solid and of the gas at any point in the rotary kiln. Understanding the heat exchanges taking place in rotary kilns is therefore crucial.

Heat transfer between the solid charge, the counter-current gas and the wall of the kiln can take place by convection, conduction, and radiation. To calculate the heat balance, it is necessary to determine the various exchange surfaces as well as the emissivities, thermal conductivities, and heat transfer coefficients. Several studies [5-7] have shown that for conversion kilns the dominant heat transfer in a cross-section of the kiln is transfer between the solid and the wall, followed by solidto-gas transfer, and then by gas-to-wall transfer. Calculation of the temperature profile of the powder flowing through a rotary kiln therefore strongly depends on the solid/wall heat transfer coefficient $\left(\mathrm{h}_{\mathrm{sw}}\right)$ that is used.

Various correlations are reported in the literature for estimating the heat transfer coefficient $h_{\text {sw }}$. Table 1 gives the $h_{\text {sw }}$ values calculated from some of these correlations [8-12] for the 
dimensions and typical operating conditions of an industrial kiln used for uranium conversion (diameter a bit less than $1 \mathrm{~m}$ and $\mathrm{L} / \mathrm{D}$ ratio greater than 10). Most of the correlations mentioned in Table 1 have been obtained thanks to data measured in industrial kilns and thus can be used for the kiln chosen as an example. Other correlations have also been published [13-16], mainly based on penetration theory. It can be clearly seen in Table 1 that the heat transfer coefficient values obtained by using these correlations are highly scattered. Moreover, as experimental measurements of heat transfer in rotary kilns are scarce, the correlations were determined or validated from a limited amount of experimental data [10, 15-17].

The aim of the present study is therefore to design and construct an adaptable experimental setup to determine primarily the heat transfer coefficient between the wall of a rotary kiln and the solid flowing through the kiln. A key point in our approach is that the operating mode (and the main technical characteristics) of the experimental setup must be similar to those of the rotary kilns used for the conversion of uranium. In particular, our kiln is externally heated and equipped with lifters so as to investigate the influence of the latter on heat transfer.

The article is organised as follows: after a brief summary of experimental rotary kilns reported in the literature, the design of our experimental apparatus is described, focusing particularly on the heating mode chosen and on the instrumentation. The preliminary results obtained with this pilot-scale kiln are also presented. 


\section{Previous experimental equipments}

As mentioned above, experimental studies of heat transfer in rotary kilns are relatively scarce. The most relevant ones involved large-scale kilns equipped with internal heating systems such as burners, or alternatively used air that had been preheated before being introduced into the rotating cylinder containing the solid. Other studies concerned kilns externally heated by steam or resistors.

There are currently three main types of experimental setups in use.

\subsection{Internal heating using hot gas}

Tscheng and Watkinson [10] constructed an experimental rotary kiln with a length (L) of $2.44 \mathrm{~m}$ and an internal diameter (D) of $0.19 \mathrm{~m}$, giving an L / D ratio of 12.8. In this type of setup, the kiln was continuously fed with solid by a screw feeder. The kiln was also fed with preheated air flowing counter-current to the solid. As the water vapor and $\mathrm{CO}_{2}$ content of air is very low, gas to wall and gas to solids radiation could be neglected. These experiments were mainly conducted with sand (particle diameter ca. $0.7 \mathrm{~mm}$ ).

Thermocouples were inserted in the bed, in the gas, and close to the rotating wall. The thermocouples were fixed to the rotating cylinder and positioned such that temperature measurements were made at the same axial locations. It was assumed that the gas phase and solid phase were in plug flow and at uniform temperatures at each axial position.

With this setup, the authors quantified the heat transfer coefficients from gas to wall $\left(\mathrm{h}_{\mathrm{gw}}\right)$, from gas to solid $\left(\mathrm{h}_{\mathrm{gs}}\right)$, and from solid to wall $\left(\mathrm{h}_{\mathrm{sw}}\right)$ by studying the influence of several parameters such as the inclination angle of the kiln, its rotational speed, the mass flow rate of the gas, the solid feed rate, and particle size.

\subsection{Internal heating with a burner}

Most industrial rotary kilns are internally heated by a burner. This was the heating mode adopted by Brimacombe and Watkinson [17-19] for the construction of a pilot rotary kiln $5.5 \mathrm{~m}$ in length and with an inside diameter of $0.406 \mathrm{~m}$ (giving an L / D ratio of 13.6). The burner was fed by a mixture of natural gas and air, and here again the solid used was sand with a mean particle size of $0.6 \mathrm{~mm}$. 
The kiln was equipped with 52 thermocouples for temperature measurements of the gas, solid, and wall. The thermocouples were fixed to the kiln wall and thus rotate with it.

As in the above study the solids temperatures and inner wall temperatures were very close together, the heat flow rate between the wall and the solid was neglected in order to simplify the data processing. The authors' main focus was on estimating the heat flux between the gas and the wall, and between the gas and the solid.

Dhanjal et al. [20] studied radial heat exchange in a bed of varying particle-size distributions inside a short kiln $(\mathrm{L} / \mathrm{D}=1.5)$ internally heated by a burner, and developed a model based on the active layer.

\subsection{External heating}

Few experimental studies have been undertaken on externally heated rotary kilns. To investigate heat transfer in this type of kiln, Lehmberg et al. [16] used a horizontal copper cylinder $0.6 \mathrm{~m}$ in length and $0.25 \mathrm{~m}$ in diameter $(\mathrm{L} / \mathrm{D}$ ratio $=2.4)$. After filling the cylinder with solid, it was closed, set into rotation and heated to $200^{\circ} \mathrm{C}$ until homogenisation. The heating was then stopped and the copper wall of the kiln was cooled by spraying water on it. A constant wall temperature was maintained by spraying and the solid particles were cooled. During the cooling process, heat transfer was studied using thermocouples to register the temperatures of the wall and the particle bulk. Experiments were conducted with various sand particle diameters in order to study the impact of particle size on heat transfer.

Suzuki et al. [21] measured the solid/wall heat transfer coefficient during the combustion of waste in an externally-heated batch-type rotary-kiln pyrolyzer $(\mathrm{L}=1.5 \mathrm{~m}, \mathrm{D}=1 \mathrm{~m}$; $\mathrm{L} / \mathrm{D}=1.5)$. Their pyrolytic kiln was externally heated using the combustion exhaust of natural gas. Temperature measurements taken at different locations within the thick cylinder wall showed that the heat exchange coefficients for waste composed of paper, wood, polyethylene, polypropylene, polystyrene and grain, when burnt at temperatures between 450 and $650^{\circ} \mathrm{C}$, was about 20 to $50 \mathrm{~W} \mathrm{~m}^{-2} \mathrm{~K}^{-1}$. They observed a slight increase in the coefficient with the number of lifters, their height, and the rotational speed of the cylinder [22].

Wes et al. [15] used an industrial-scale reactor $(\mathrm{L}=9 \mathrm{~m}, \mathrm{D}=0.6 \mathrm{~m} ; \mathrm{L} / \mathrm{D}=15)$ to study heat transfer in rotary kilns. The cylinder was charged with potato starch and the kiln heated by steam flowing around the rotating cylinder. The cylinder temperature was recorded by a 
thermocouple and was taken to be constant along the cylinder length. The gas and solid temperatures were measured by several thermocouples positioned along the cylinder.

To estimate the heat transfer coefficient between the wall and the bulk solid $\left(\mathrm{h}_{\mathrm{sw}}\right)$, no air was passed through the cylinder during the experiments. The heat transfer coefficient between the wall and the gas $\left(\mathrm{h}_{\mathrm{gw}}\right)$ was measured in an empty kiln.

As the above summary makes clear, there is a lack of experimental studies of heat transfer in rotating cylinders. Not only have studies often been performed in specific conditions of heating mode or particle movement, but the results obtained are seldom comparable or applicable to different operating conditions.

We therefore decided to design a new experimental rotary kiln that is both versatile and fully instrumented so as to study heat transfer in conditions comparable to those encountered in the industrial rotary kilns used for the conversion of uranium. 


\section{Experimental device}

\subsection{General description}

As can be seen on Figures 1 and 2, the experimental device comprises a rotating cylinder in Inconel, an external heating system, a solid feed system and a tank for the recovery of the solid after it has passed through the kiln. The rotating cylinder has a length of $1.95 \mathrm{~m}$, an outer diameter of $0.114 \mathrm{~m}$ and an inner diameter of $0.101 \mathrm{~m}$. The $\mathrm{L} / \mathrm{D}$ ratio is therefore greater than 19 . The inside wall of the cylinder is smooth.

The device is equipped with a hopper for storage of the solid. The rotating cylinder is fed with solid by means of a loading chute and a feed screw located beneath the hopper. The feed screw and the cylinder are rotated by two variable frequency electric motors. The solid exiting the cylinder is collected in a tank. A control box placed at the lower end of the cylinder monitors the inflow of gas into the cylinder during the heating phase. The gas flow rate can be varied from 0 to $7 \mathrm{Nm}^{3} \mathrm{~h}^{-1}$.

The outer wall of the rotating cylinder is heated by a furnace equipped with heating resistors. The furnace comprises two identical and independent heating zones (see Fig. 1), each measuring $40 \mathrm{~cm}$ and placed side by side. The heating resistors are insulated, the whole forming the heating device, which is placed around the rotating cylinder. The maximum power that can be delivered by the heating elements is $10 \mathrm{~kW}$, with each zone delivering a power of $5 \mathrm{~kW}$.

\subsection{Variable parameters}

The apparatus was designed to be adaptable so as to enable the study of the influence of many different parameters on heat transfer. Table 2 lists the variable parameters of the setup.

The angle of kiln inclination can be manually adjusted between $0^{\circ}$ and $5^{\circ}$; this corresponds to industrial kilns, in which the tilt angle does not exceed $5^{\circ}$.

A wide range of rotational speeds is possible by means of the variable frequency motor. This range can be further extended by replacing one of the driving pinions of the cylinder. The rotational speed can be varied from 0.5 to $12 \mathrm{rpm}$. Note that the rotational speed of industrial rotary kilns is always well below $10 \mathrm{rpm}$. Obviously, it is difficult to compare an industrial kiln and a laboratory kiln operating at the same rotational speed since there is a large difference in solid flow rate. 
However, we chose the widest possible range of rotational speed in order to avoid to be restricted in the study of this parameter influence.

The rotational speed of the feed screw is also adjustable within the range of 0.5 to $12 \mathrm{rpm}$. Given the properties of the sand used in the experiments, the solid flow rate can be varied between 1.5 and $7.5 \mathrm{~kg} \mathrm{~h}^{-1}$.

Dams can be placed at the end of the rotating cylinder, making it possible to select the height of the solid bed at the cylinder exit between 0 and $33.5 \mathrm{~mm}$, and to vary the filling ratio of the kiln irrespective of the solid flow rate and the cylinder rotational speed.

With the heating power installed, the temperature of the solid passing through the kiln can reach $1000^{\circ} \mathrm{C}$.

Since rotary kilns for the conversion of uranium are fitted with lifters, one of the goals of our study was to quantify the possible influence of the presence of lifters on heat transfer. The setup was therefore designed to operate with and without lifters. Removable lifters, made of the same material as the rotating cylinder, can be fixed to the inner wall of the cylinder and rotate with it in order to mix the solid. Figure 3 shows the lifters fitted to the rotating cylinder in the presence of solid.

\subsection{Temperature measurements}

Particular attention was paid to the instrumentation of the kiln, since in order to calculate the heat balance, it is essential to know the exact temperatures of the wall, the gas and the solid at any point in the kiln. To achieve this, the device was equipped with 36 thermocouples spaced in 4 series along the length of the cylinder (positions 1, 2(1), 2(2) et 2(3) on figure 1).

4 series of $4 \mathrm{~K}$-type thermocouples were placed on the outside of the cylinder, as close as possible to the rotating wall. To insert the thermocouples, small holes were drilled in the heating unit. The tip of the thermocouples was located in the space between the heating resistors and the outer wall of the cylinder (see Fig. 4a and Fig. 5). The thermocouples are $3 \mathrm{~mm}$ in diameter and their tips are sheathed in ceramic to protect them from the radiation emitted by the heating resistors.

In order to validate the measurements recorded by the external thermocouples, the temperature of the outside wall of the cylinder was measured with a pyrometer via a hole in the heating unit.

Lastly, to measure temperatures up to $1300^{\circ} \mathrm{C}, 4$ series of $5 \mathrm{~N}$-type thermocouples $1.5 \mathrm{~mm}$ in diameter were placed inside the rotating cylinder on a rod made of the same material as the 
cylinder (see Figure 4b). These 5 thermocouples measure the temperature of the gas (3 thermocouples per series) and of the solid (2 thermocouples per series) (see Fig. 5). The rod is removable and is introduced along the kiln axis; its external diameter is $21 \mathrm{~mm}$. The rod and internal thermocouples remain fixed during rotation of the kiln. To limit the mass and surface of metal inside the kiln, the dimensions of the rod were as small as possible. The axial positions of the internal and the external thermocouples were identical. Figure 5 shows the arrangement of the two series of thermocouples for a given cross-section of the kiln.

As the kiln can operate with and without lifters, two rods were constructed: one for the experiments without lifters, the other for the experiments with lifters. The main difference between the two rods is the distance between the tip of the thermocouples and the inside wall of the cylinder. In the experiments conducted with lifters, the thermocouples need to be placed at a certain distance from the wall so as to avoid any contact between the rotating lifters and the fixed thermocouples.

It is important to note that only two internal thermocouples are in contact with the solid in the kiln, and that the rods are hollow to enable the passage of the extension wires connecting the thermocouples to the data acquisition system. The operating parameters of the device and the temperatures were recorded at regular intervals and then processed.

The angle of repose formed by the solid in the rotary kiln depends, among other things, on the shape and particle size of the solid. In order to adapt the technique to different types of solid, the angle of the rod supporting the internal thermocouples can be adjusted so as to maintain a right angle between the thermocouples inserted into the bed and the bed surface. The heating unit can also be adjusted slightly around the cylinder to ensure that the internal and external thermocouples are always opposite each other.

\subsection{Materials}

The physical properties of the sand used for the experiments are listed in Table 3. The mean particle size was $0.54 \mathrm{~mm}$, the bed density was $1420 \mathrm{~kg} \mathrm{~m}^{-3}$ and the static angle of repose approximately 39 degrees. The static angle of repose of the sand has been measured using the fixed cone method: the powder flows out of a funnel and forms a heap from which the static angle of repose can be estimated.

Thermal conductivity, specific heat and sand emissivity were not measured; the values given in table 3 are those reported by $[3,10,12]$. 


\section{Preliminary tests and results}

\subsection{Axial and transverse motion of sand}

Before undertaking the heat study experiments, it was important to check the correct hydrodynamic operation of the pilot kiln and to quantify the mean residence time. We therefore conducted repeated measurements of the residence time distribution under the nominal operating conditions of the setup, to ascertain that the flow in the pilot was a plug flow with low axial dispersion. The pilot was therefore operated cold for at least 5 hours with a solid feed rate of $2.5 \mathrm{~kg} \mathrm{~h}^{-1}$, a rotational speed of $3 \mathrm{rpm}$, a $23.5 \mathrm{~mm}$ dam and an inclination angle of $2^{\circ}$. As it could then be considered that from a hydrodynamic point of view the steady-state regime had been reached, we promptly introduced $12 \mathrm{~g}$ of red sand grains into the inlet of the rotating cylinder (just downstream the feed screw outlet). We thus made a pulse tracer input signal. For residence time distribution experiments, it is necessary that the tracer properties be the same as those of the normal charge entering the system. That is why coloured sand was used as tracer in our experiments.

After the impulse tracer input, samples of $3.4 \mathrm{~g}$ of sand were collected at the cylinder outlet every $30 \mathrm{~s}$. To describe the concentration-time function of tracer in the exit stream of the cylinder, the red grains were sorted out from the samples and weighed with a precision balance, enabling the residence time distribution function shown on Figure 6 to be determined. Indeed, at each collected sample corresponds a time $\left(\mathrm{t}_{\mathrm{i}}\right)$ and a mass of tracer $\left(\mathrm{m}_{\mathrm{i}}\right)$. The RTD function shown on Figure 6 was obtained using the equation

RTD function $=E(t)=\frac{m_{i}(t)}{\int_{0}^{\infty} m_{i}(t) d t}$

The results obtained demonstrate first that the trial can be correctly reproduced, and second that peak broadening is negligible. The mean residence time in these operating conditions is 46.5 min and the variance is $2.2 \mathrm{~min}^{2}\left(610^{-4} \mathrm{~s}^{2}\right)$. The Peclet number is therefore extremely high (around 2000), as is usual for rotary kilns with a high L / D ratio [23-25]. The flow regime in our pilot-kiln can thus be considered to be a plug flow with low axial dispersion. The results further show that five hours is ample time to establish the regime before undertaking RTD measurements.

Concerning the transverse bed motion, visual observations allowed us to conclude that the bed is in rolling mode in the investigated rotational speed and kiln inclination range. Indeed, the bed shows a constant angle of inclination and a flat planar surface. There is no slipping of the bed against the wall. Moreover, the Froude number was calculated under the nominal operating 
conditions (above-mentioned) of our experimental device. The result obtained is Fr $=1.610^{-4}$. This value is in the range of Froude numbers corresponding to the rolling mode according to Mellmann [26]. Even if the Froude number is an insufficient criterion to characterize bed behaviour, this result confirms our visual observations.

\subsection{Validation of the steady state}

The study detailed above enabled us to quantify the time required to establish the hydrodynamic regime. With a near-perfect plug flow, it was thus ascertained that twice the mean residence time is more than sufficient to attain steady-state from the hydrodynamic point of view.

The next step was to determine the heat regime. The pilot was therefore set in operation with a solid feed rate of $2.5 \mathrm{~kg} \mathrm{~h}^{-1}$, a rotational speed of $3 \mathrm{rpm}^{-1}$, a dam of $23.5 \mathrm{~mm}$ and an inclination angle of $2^{\circ}$. A further specification was to apply a temperature of $600^{\circ} \mathrm{C}$ to zone 2 . Figure 7 shows the temperature readings of certain thermocouples as a function of time (cf. figure legends on Figures 1 and 5). It can be seen on Figure 7a that after $5 \mathrm{hrs}$ the temperatures appear to level off. Figure $7 \mathrm{~b}$ shows the profiles obtained after $5 \mathrm{hrs}$ in greater detail, confirming that steady state is reached in five hours. The power box displays a perfectly constant value of power consumed (to within $10 \mathrm{~W}$, out of $0.83 \mathrm{~kW}$ ), thus confirming that when the temperatures are stable, steady state has been attained from the thermal point of view.

In all our experiments to determine the value of the solid/wall heat transfer coefficient, the pilot-kiln was therefore operated for 5 to $5.5 \mathrm{~h}$ and the time-averaged temperatures were then calculated during the half-hour following this period in order to represent the steady state operation of the setup.

\subsection{Heat balance}

Measurements were made in steady state without lifters, with a continuous flow of sand and no circulation of air (the gas inlet and outlet of the rotating cylinder were closed).

The measurement points 2(1) and 2(3) are considered respectively to be the entry and exit points of our system where the heat balance was determined; the measurement point 2(2) corresponds to the inside of the system. The heat flow required to heat the solid moving through the system is therefore:

$$
\dot{\mathrm{m}}_{\mathrm{S}} \cdot \mathrm{Cp}_{\mathrm{s}} \cdot\left(\mathrm{Ts}_{2(3)}-\mathrm{Ts}_{2(1)}\right)
$$


The net radiative flux between the solid and the wall is:

$$
\varepsilon_{\mathrm{S}} \cdot \varepsilon_{\mathrm{W}} \cdot\left(1-\varepsilon_{\mathrm{g}}\right) \cdot \mathrm{F} \cdot \mathrm{A}_{\mathrm{sg}} \cdot \sigma \cdot\left(\operatorname{Tp}_{2(2)}{ }^{4}-\mathrm{Tw}_{2(2)}{ }^{4}\right)
$$

The net radiative flux between the solid and the gas is:

$\varepsilon_{\mathrm{S}} \cdot \varepsilon_{\mathrm{g}} \cdot \mathrm{A}_{\mathrm{sg}} \cdot \sigma \cdot\left(\operatorname{Ts}_{2(2)}{ }^{4}-\mathrm{Tg}_{2(2)}{ }^{4}\right)$

The heat fluxes exchanged by modes other than radiation between the solid and the wall, and between the solid and the gas, are respectively:

$\mathrm{h}_{\mathrm{sW}} \cdot \mathrm{A}_{\mathrm{sW}} \cdot\left(\mathrm{Ts}_{2(2)}-\mathrm{Tw}_{2(2)}\right)$

and

$\mathrm{h}_{\mathrm{sg}} \cdot \mathrm{A}_{\mathrm{sg}} \cdot\left(\mathrm{Ts}_{2(2)}-\mathrm{Tg}_{2(2)}\right)$

The mass flow of the sand $\mathrm{m}_{\mathrm{S}}$ was imposed and checked at the outlet of the cylinder. The heat capacity of the sand $\mathrm{Cp}_{\mathrm{s}}$ is given in Table 3 . The solid/gas heat transfer coefficient $\mathrm{h}_{\mathrm{sg}}$ was estimated to be $3 \mathrm{~W} \mathrm{~m}^{-2} \mathrm{~K}^{-1}$ using a correlation that is applicable to natural convection above a horizontal solid plane for air in the temperature range measured by our pilot-kiln [27]; the solid/wall heat transfer coefficient $h_{s w}$ is the magnitude to be determined. The heat exchange areas between solid and gas $\mathrm{A}_{\mathrm{sg}}$, and between solid and wall $\mathrm{A}_{\mathrm{sw}}$, were calculated as a function of the filling degree of the cylinder; the filling degree was experimentally determined by completely emptying the cylinder after stopping the sand feed. As the mass and the bulk density of the sand in the cylinder are known (see Table 3), the volume occupied by the solid can be calculated, and was found to be:

$$
\mathrm{R}^{2} \cdot \frac{\Gamma-\sin \Gamma}{2} \cdot \mathrm{L}
$$

$\mathrm{R}$ is the cylinder radius, $\Gamma$ the filling angle and $\mathrm{L}$ the total length of the rotating cylinder (the error due to the shape of the powder bed is minimal as the bed is almost flat). Using the value of the filling angle thus obtained, the exchange surfaces for the heat balance can be calculated:

$$
\mathrm{A}_{\mathrm{sg}}=2 \cdot \mathrm{R} \cdot \sin \left(\frac{\Gamma}{2}\right) \cdot \mathrm{L}_{\text {balance }}
$$

and

$$
\mathrm{A}_{\mathrm{sW}}=\Gamma \cdot \mathrm{R} \cdot \mathrm{L}_{\text {balance }}
$$

$\mathrm{L}_{\text {balance }}$ is the length of the system on which the heat balance was measured, i.e. the distance between the measurement points 2(1) and 2(3), or $200 \mathrm{~mm}$. The Stefan-Boltzmann constant was taken to be $5.6710^{-8} \mathrm{~W} \mathrm{~m}^{-2} \mathrm{~K}^{-1}$. The emissivity of the cylinder (Allegheny Ludlum 800HT, nickel- 
base alloy) is 0.9 [manufacturer's data]. The emissivity of the sand is given in Table 3 . The air is mainly composed of symmetrical diatomic gases and can therefore be considered to be transparent. Given the ambient humidity in the laboratory, the emissivity of the air is below 0.01 [28], meaning that the radiative exchange term with the gas can be neglected. The correction factor for our geometry [29] is:

$$
\mathrm{F}=\frac{1}{\frac{1-\varepsilon_{\mathrm{s}}}{\varepsilon_{\mathrm{s}}}+1+\frac{1-\varepsilon_{\mathrm{w}}}{\varepsilon_{\mathrm{w}}} \cdot \frac{\mathrm{A}_{\mathrm{sg}}}{\mathrm{A}_{\mathrm{wg}}}} \text { with } \mathrm{A}_{\mathrm{wg}}=(2 \pi-\Gamma) \cdot \mathrm{R} \cdot \mathrm{L}_{\text {balance }}
$$

All the temperatures were obtained from the time-averaged temperatures measured by the thermocouples during the half-hour following at least 5 to $5.5 \mathrm{~h}$ of steady-state regime. The temperature of the solid, Ts, was calculated by averaging the temperature registered by the thermocouple inserted in the sand close to the wall (Tsw on Fig. 5) and the thermocouple inserted in the sand slightly above (Tsi) when the difference between the two was less than $10^{\circ} \mathrm{C}$. Any difference in excess of $10^{\circ} \mathrm{C}$ means that the thermocouple measuring Tsi does not in fact penetrate the sand because the bed is too shallow; in this case we took Ts = Tsw. The temperature of the gas, $\mathrm{Tg}$, was measured by the thermocouple plunged in the gas in close proximity to the solid (Tg on Fig. 5). The wall temperature, Tw, was calculated by averaging the temperatures registered by the thermocouples placed around the wall (they are close to one another, as can be seen in Table 4).

The heat balance in steady state can therefore be written:

$$
\begin{aligned}
& \dot{\mathrm{m}}_{\mathrm{s}} \cdot \mathrm{Cp}_{\mathrm{s}} \cdot\left(\mathrm{Ts}_{2(3)}-\mathrm{Ts}_{2(1)}\right) \\
& +\mathrm{h}_{\mathrm{sg}} \cdot \mathrm{A}_{\mathrm{sg}} \cdot\left(\mathrm{Ts}_{2(2)}-\mathrm{Tg}_{2(2)}\right) \\
& +\mathrm{h}_{\mathrm{sw}} \cdot \mathrm{A}_{\mathrm{sw}} \cdot\left(\mathrm{Ts}_{2(2)}-\mathrm{Tw}_{2(2)}\right) \\
& +\mathrm{A}_{\mathrm{sg}} \cdot \sigma \cdot\left[\varepsilon_{\mathrm{s}} \cdot \varepsilon_{\mathrm{w}} \cdot\left(1-\varepsilon_{\mathrm{g}}\right) \cdot \mathrm{F} \cdot\left(\mathrm{Ts}_{2(2)}{ }^{4}-\mathrm{Tw}_{2(2)} 4\right)+\varepsilon_{\mathrm{s}} \cdot \varepsilon_{\mathrm{g}} \cdot\left(\mathrm{Ts}_{2(2)}{ }^{4}-\mathrm{Tw}_{2(2)} 4\right)\right] \\
& =0
\end{aligned}
$$

Neglecting the radiative exchange term with the gas as explained above, the solid to wall heat transfer coefficient can be written:

$$
\mathrm{h}_{\mathrm{sw}}=\frac{\dot{\mathrm{m}}_{\mathrm{s}} \cdot \mathrm{Cp}_{\mathrm{s}} \cdot\left(\operatorname{Ts}_{2(3)}-\mathrm{Ts}_{2(1)}\right)+\mathrm{h}_{\mathrm{sg}} \cdot \mathrm{A}_{\mathrm{sg}} \cdot\left(\operatorname{Ts}_{2(2)}-\mathrm{Tg}_{2(2)}\right)+\mathrm{A}_{\mathrm{sg}} \cdot \sigma \cdot \varepsilon_{\mathrm{s}} \cdot \varepsilon_{\mathrm{w}} \cdot\left(1-\varepsilon_{\mathrm{g}}\right) \cdot \mathrm{F} \cdot\left(\operatorname{Ts}_{2(2)}{ }^{4}-\mathrm{Tw}_{2(2)}{ }^{4}\right)}{\mathrm{A}_{\mathrm{sw}} \cdot\left(\mathrm{Tw}_{2(2)}-\mathrm{Ts}_{2(2)}\right)}
$$

The values used for calculation in the nominal operating case are given in Table 4; the repeated trials demonstrate the accuracy of our results. The results obtained by varying independently the mass flow rate $\mathrm{m}_{\mathrm{S}}$ and the rotational speed of the cylinder $\mathrm{N}$ are given in Table 5. It can be seen that the heat transfer coefficient $\mathrm{h}_{\mathrm{sw}}$ varies only slightly as a function of $\mathrm{N}$ in the 
range investigated, whereas Figure 8 exhibits a linear correlation between $\mathrm{h}_{\mathrm{sw}}$ and $\dot{\mathrm{m}}_{\mathrm{s}}$ for a constant rotational speed of $3 \mathrm{rpm}$.

These results may seem surprising since several previous studies reported a significant effect of the rotational speed on the wall to solid heat transfer coefficient. However, in our study, the investigated rotational speed range (from 1 to $3 \mathrm{rpm}$ ) is a bit narrow and we are planning to extend the investigated range soon.

With regard to the influence of the solid flow rate, a comparison of our results with previous literature results is very tricky. Actually, the operating conditions used in this study are very far from those used in the few experimental previous works.

Finally, let us stress that this work has been conducted because in the open literature, experimental measurements concerning the wall to solid heat transfer coefficient in our conditions (i.e. external heating, thin wall without layer of refractory) are almost nonexistent. 


\section{Conclusions}

We have designed and built an adaptable experimental device to determine the heat transfer coefficient between the wall and the solid flowing through a rotary kiln. The kiln is externally heated by an electrical heating unit comprising two independent zones to allow both the heating and the cooling of the solid charge to be studied; the rotating cylinder can also be fitted with lifters. The following parameters can be independently varied: rotational speed of the cylinder, solid flow rate, kiln inclination, bed height at the cylinder exit, and the temperatures of the two heating zones. Lastly, the device can be adapted to the specific characteristics of the powder used (in particular, the angle of repose).

The experimental procedure and the calculations developed in this study have enabled the determination of the solid/wall heat transfer coefficient under the trial conditions, thanks to temperature measurements and various other parameters. We have established that, in the nominal operating conditions of our system, and using sand as the solid charge, the solid/wall heat transfer coefficients obtained are of a comparable order of magnitude to those reported in the literature, under more or less similar operating conditions. Among the variable parameters investigated, we have found that the solid/wall heat transfer coefficient increases linearly with the solid flow rate, but that it shows negligible variation with the rotational speed of the cylinder.

Future work will focus on the influence of the other variable parameters of the setup, namely the kiln inclination, the bed height at the cylinder exit, and the heating temperature. We also plan to examine the case of cooling, the effect of particle size, and the presence of lifters

\section{Acknowledgements}

This work was supported by a grant from Areva NC. We gratefully acknowledge Pr. Bontemps, GRETh, for his kind help in this work. 


\section{SYMBOLS USED}

$\begin{array}{lll}\text { A } & {\left[\mathrm{m}^{2}\right]} & \text { area } \\ \mathrm{Cp} & {\left[\mathrm{J} \mathrm{kg}^{-1} \mathrm{~K}^{-1}\right]} & \text { specific heat } \\ \mathrm{D} & {[\mathrm{m}]} & \text { kiln diameter } \\ \mathrm{Fr} & {[-]} & \text { Froude number } \\ \mathrm{h}_{\mathrm{sg}} & {\left[\mathrm{W} \mathrm{m}^{-2} \mathrm{~K}^{-1}\right]} & \text { gas to solid heat transfer coefficient } \\ \mathrm{h}_{\mathrm{gw}} & {\left[\mathrm{W} \mathrm{m}^{-2} \mathrm{~K}^{-1}\right]} & \text { gas to wall heat transfer coefficient } \\ \mathrm{h}_{\mathrm{sw}} & {\left[\mathrm{W} \mathrm{m} \mathrm{K}^{-1}\right]} & \text { wall to solid heat transfer coefficient } \\ \mathrm{L} & {[\mathrm{m}]} & \text { kiln length } \\ \mathrm{L} & {[\mathrm{m}]} & \text { length of heat balance system } \\ \mathrm{m} & {[\mathrm{g}]} & \text { mass of tracer in a sample } \\ \bullet & & \\ \mathrm{m} & {[\mathrm{kg} \mathrm{s}]} & \text { mass flowrate } \\ \mathrm{N} & {[\mathrm{rpm}]} & \text { rotational speed } \\ \mathrm{R} & {[\mathrm{m}]} & \text { inside radius of cylinder } \\ \mathrm{T} & {[\mathrm{K}]} & \text { temperature } \\ \mathrm{t} & {[\mathrm{min}]} & \text { time }\end{array}$

Greek letters

$\begin{array}{lll}\alpha & {[\mathrm{rad}]} & \text { kiln inclination angle } \\ \varepsilon & {[-]} & \text { emissivity } \\ \eta & {[\mathrm{m}]} & \text { dam height } \\ \sigma & {\left[\mathrm{W} \mathrm{m}^{-2} \mathrm{~K}^{-1}\right]} & \text { Stefan-Boltzmann constant } \\ \Gamma & {[\mathrm{rad}]} & \text { filling angle }\end{array}$

Subscripts

2(1) first measurement position in the second heating zone

2(2) second measurement position in the second heating zone

2(3) third measurement position in the second heating zone

g gas

S $\quad$ solid (sand)

w wall 


\section{REFERENCES}

[1] R. K. Meade, Ind. Eng. Chem. 1914, 6 (9), 754. DOI: 10.1021/ie50069a015

[2] A. A. Boateng, Rotary Kilns, Butterworth-Heinemann, Oxford 2008.

[3] N. Descoins, Ph.D. Thesis, Institut National Polytechnique de Toulouse, 2003.

[4] N. Descoins, J.L. Dirion, T. Howes, Chem. Eng. Process. 2005, 44 (2), 315. DOI: 10.1016/j.cep.2004.02.025

[5] M. Debacq, Ph.D. Thesis, Institut National Polytechnique de Lorraine, Nancy, 2001.

[6] C. Nicole, Ph.D. Thesis, Institut National Polytechnique de Lorraine, Nancy, 1996.

[7] F. Hanrot, Ph.D. Thesis, Institut National Polytechnique de Lorraine, Nancy, 1992.

[8] L.H.J. Wachters, H. Kramers, in Proc. of the 3rd European Symposium on Chemical Reaction Engineering, Pergamon Press, Oxford 1964.

[9] G. Dumont, P.R. Belanger, Ind. Eng. Chem. Process Des. Dev. 1978, 17 (2), 107. DOI: 10.1021/i260066a001

[10] S.H. Tscheng, A.P. Watkinson, Can. J. Chem. Eng. 1979, 57 (4), $433 . \quad$ DOI: 10.1002/cjce.5450570405

[11] M. Imber, V. Paschkis, Int. J. Heat Mass Transfer 1962, 5 (7), 623. DOI: 10.1016/00179310(62)90086-8

[12] P. Lybaert, Int. J. Heat Mass Transfer 1987, 30 (8), $1663 . \quad$ DOI: 10.1016/00179310(87)90312-7

[13] S.Q. Li, L.B. Ma, W. Wan, Q. Yao, Chem. Eng. Technol. 2005, 28 (12), 1480. DOI: 10.1002/ceat.200500241

[14] J.R. Ferron, D.K. Singh, AIChE J. 1991, 37 (5), 747. DOI: 10.1002/aic.690370512

[15] G.W.J. Wes, A.A.H. Drinkenburg, S. Stemerding, Powder Technol. 1976, 13 (2), 185. DOI: 10.1016/0032-5910(76)85003-6

[16] J. Lehmberg, M. Hehl, K. Schügerl, Powder Technol. 1977, 18 (2), 149. DOI: 10.1016/00325910(77)80004-1

[17] J.K. Brimacombe, A.P. Watkinson, Metall. Trans. B 1978, 9 (3), 201. DOI: 10.1007/BF02653685

[18] A.P. Watkinson, J.K. Brimacombe, Metall. Trans. B 1978, 9 (3), $209 . \quad$ DOI: 10.1007/BF02653686

[19] P.V. Barr, J.K. Brimacombe, A.P. Watkinson, Metall. Trans. B 1989, 20 (3), 391. DOI: 10.1007/BF02696991 
[20] S.K. Dhanjal, P.V. Barr, A.P. Watkinson, Metall. Trans. B 2004, 35 (6), 1059. DOI: 10.1007/s11663-004-0062-0

[21] T. Suzuki, T. Okazaki, K. Yamamoto, H. Nakata, O. Fujita, J. Therm. Sci. Technol. 2008, 3 (3), 523. DOI: 10.1299/jtst.3.523

[22] T. Suzuki, T. Okazaki, K. Yamamoto, H. Nakata, O. Fujita, J. Therm. Sci. Technol. 2008, 3 (3), 532. DOI: $10.1299 /$ jtst.3.532

[23] P.S.T. Sai, G.D. Surender, A.D. Damodaran, V. Suresh, Z.G. Philip, K. Sankaran, Metall. Trans. B 1990, $21 B(6), 1005$. DOI: 10.1007/BF02670271

[24] T. Kohav, J.T. Richardson, D. Luss, AIChE J. 1995, 41 (11), $2465 . \quad$ DOI: 10.1002/aic.690411112

[25] E. Lebas, F. Hanrot, D. Ablitzer, J.L. Houzelot, Can. J. Chem. Eng. 1995, 73 (2), 173. DOI: $10.1002 /$ cjce. 5450730202

[26] J. Mellmann, Powder Technol. 2001, 118 (3), 251. DOI: 10.1016/S0032-5910(00)00402-2

[27] R.H. Perry, Perry's chemical engineers' handbook, $7^{\text {th }}$ Ed., McGraw-Hill, New-York 1997.

[28] J.R. Welty, C.E. Wicks, R.E. Wilson, Fundamentals of Momentum, Heat and Mass Transfer, Wiley, New-York 1969.

[29] De Vriendt, La transmission de la chaleur - Introduction au rayonnement thermique, $3^{\mathrm{e}} \mathrm{Ed}$, Gaëtan Morin Éditeur, Québec 1992. 


\section{FIGURES}

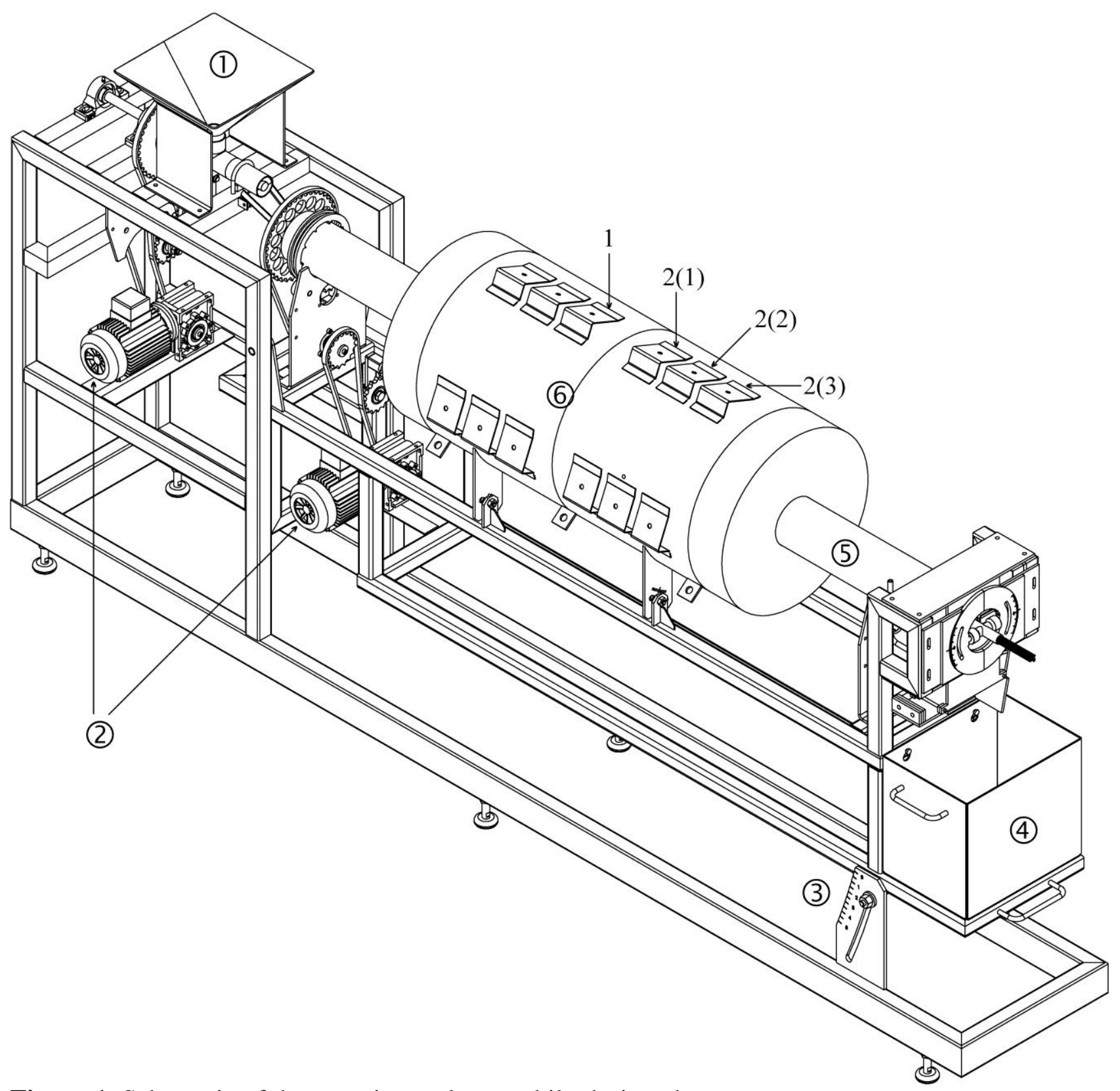

Figure 1. Schematic of the experimental rotary kiln designed.
(1) Solid hopper and feed screw
(2) Electric motors for the screw and kiln rotation
(3) Kiln inclination adjustment device
(5) Rotary kiln
(4) Solid recovery tank
( Electric heating device with two heating zones 


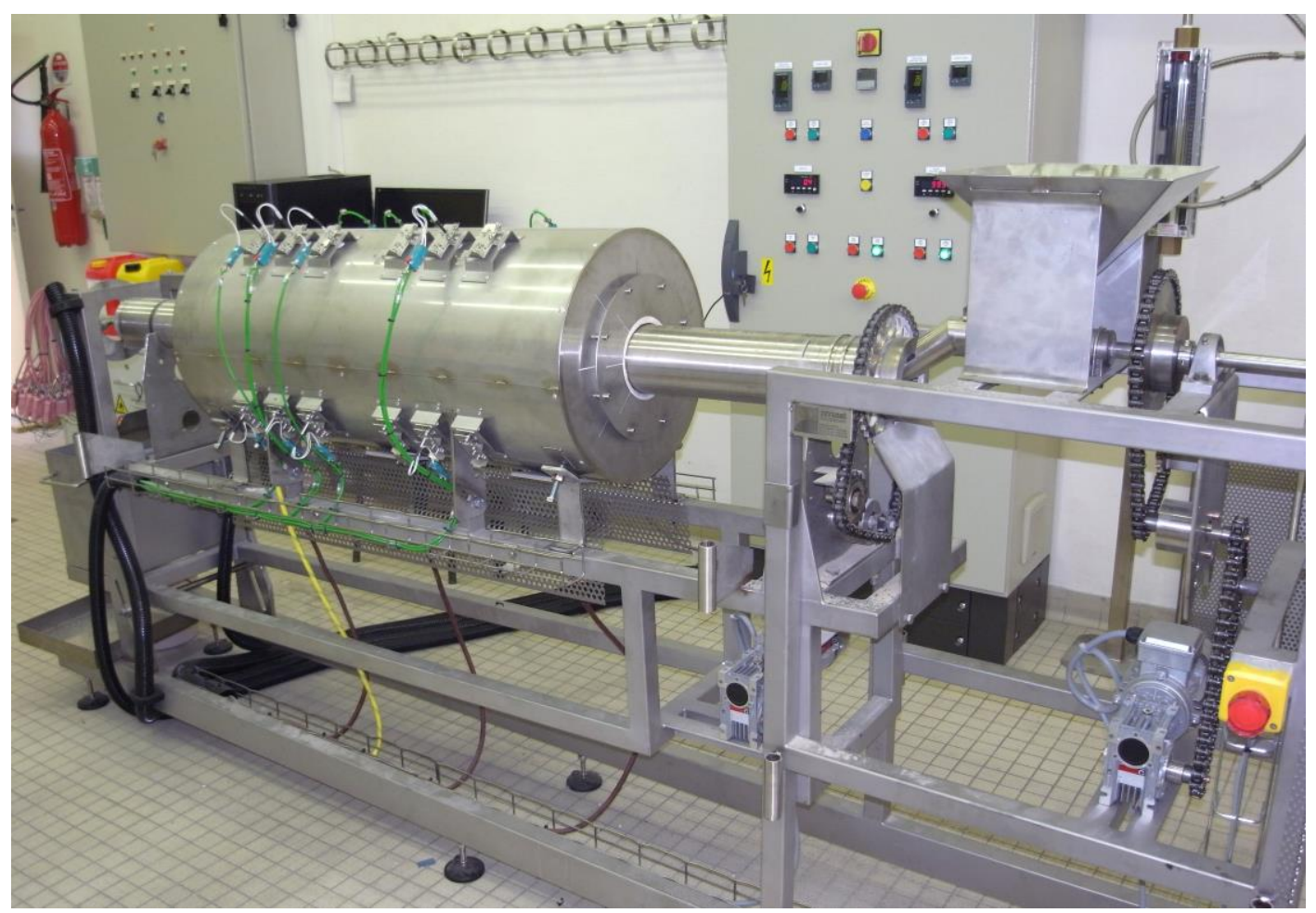

Figure 2. Photograph of the experimental setup.

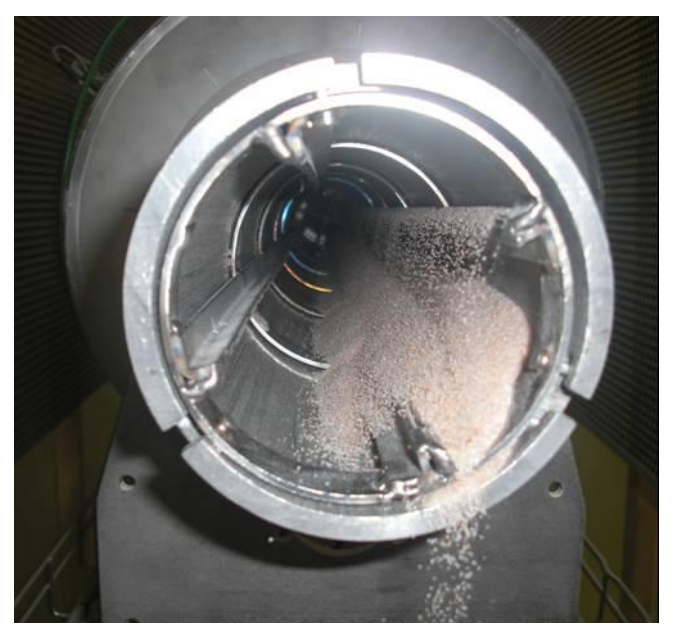

Figure 3. Photograph of the experimental rotary kiln equipped with lifters.

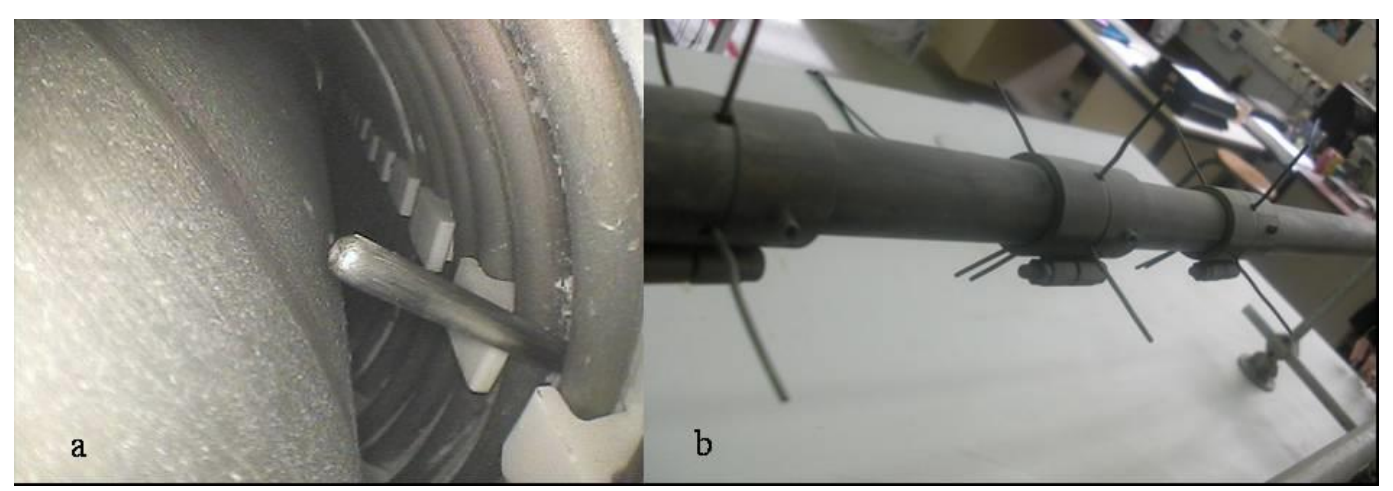

Figure 4. a) External temperature measurement. Thermocouples are placed between the electrical resistance and the external cylinder wall. b) Internal temperature measurement. At a given section, five thermocouples are used to measure the solid and gas temperatures at different radial positions in the rotary kiln. 


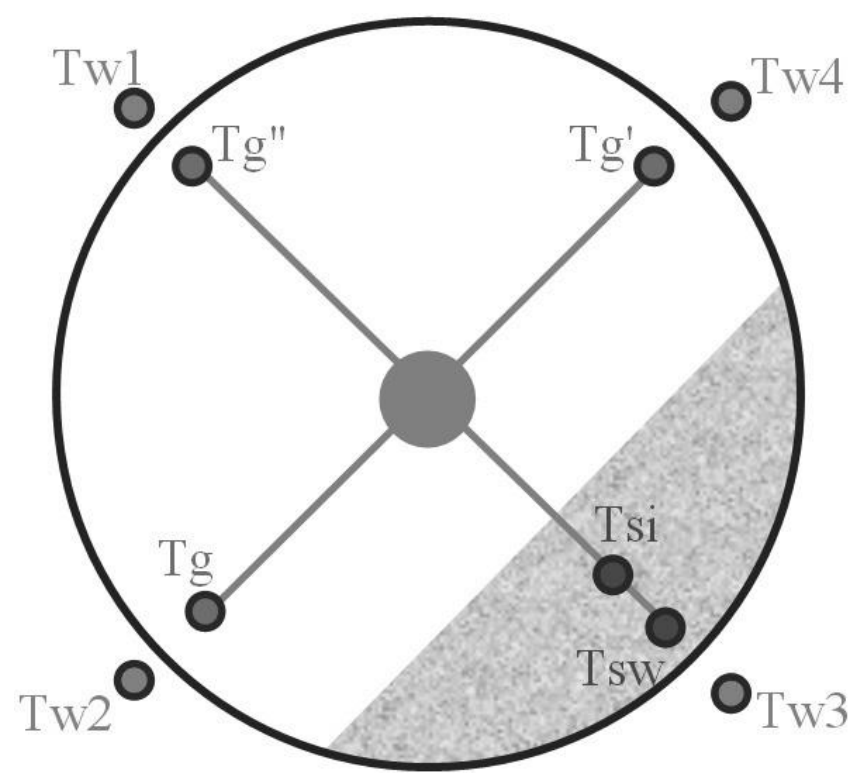

Figure 5. Thermocouple positions in a cross section of the rotary kiln. 4 external thermocouples to measure the wall temperature. 3 internal thermocouples to measure the gas temperature in the kiln. 2 internal thermocouples to measure the bed temperature. This measurement device is repeated four times along the kiln in the heating zone. The positions of the four devices are specified in Fig 1. $(1,2(1), 2(2)$ and 2(3)).

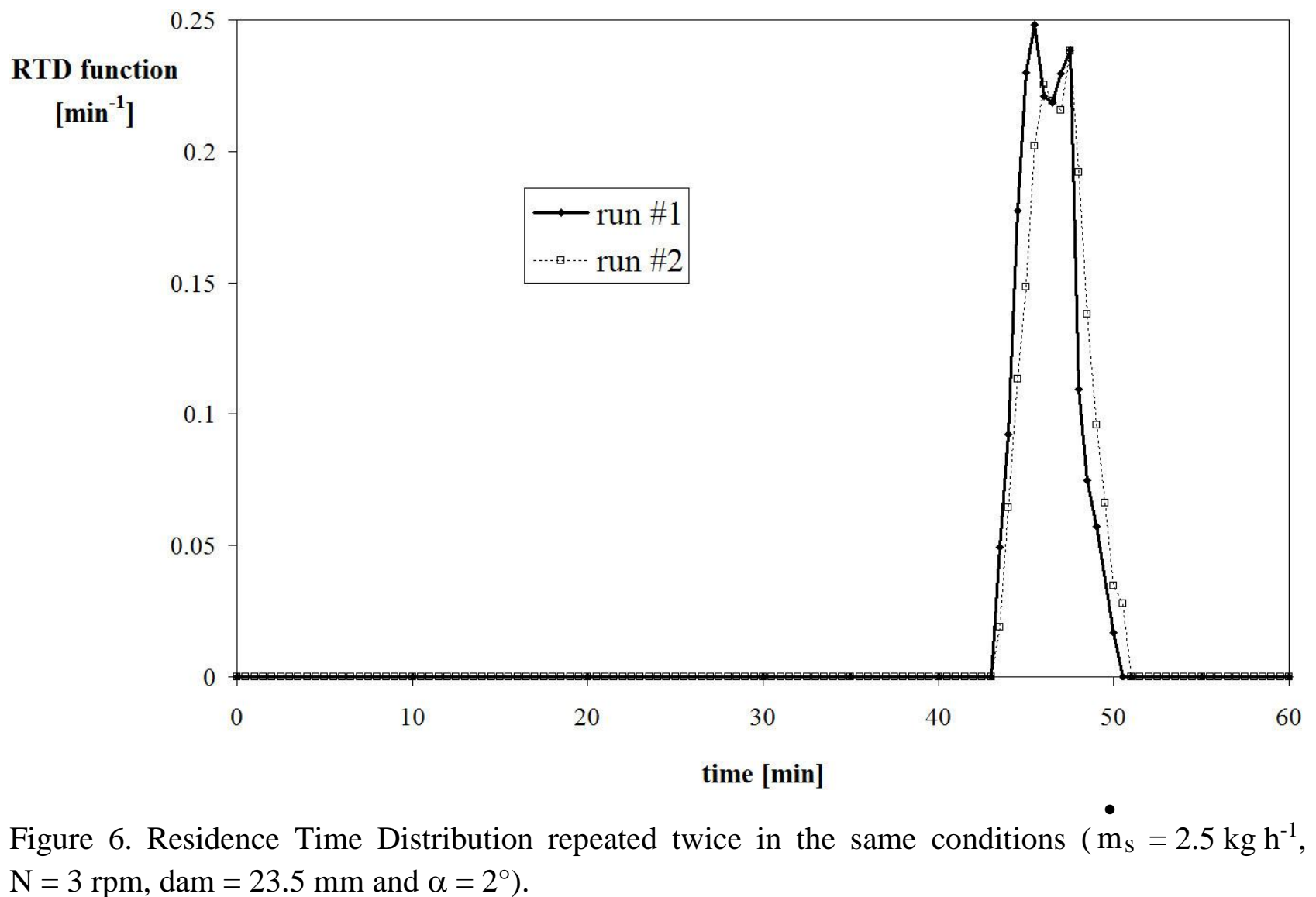



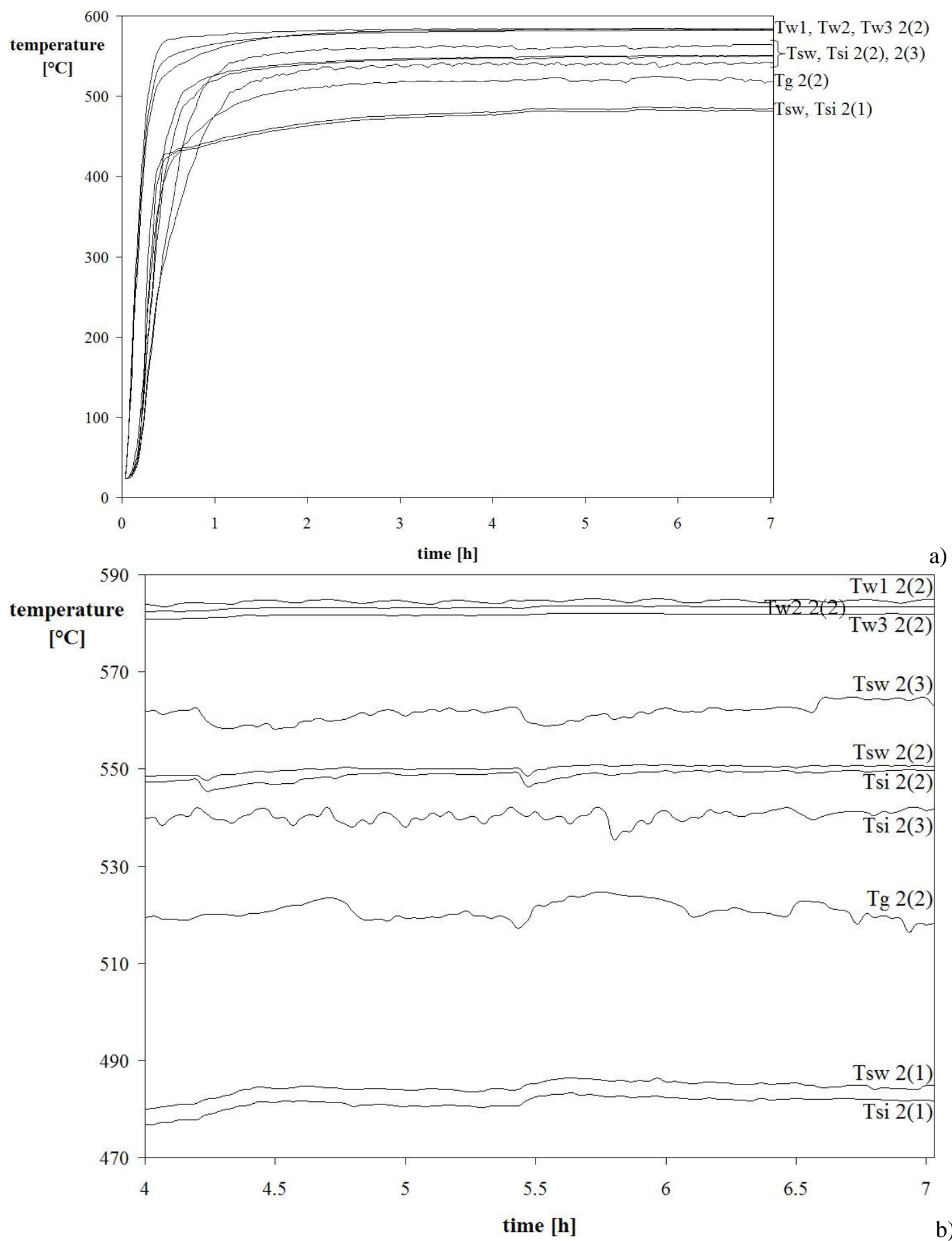

Figure 7. Temperatures as a function of time: a) long run; b) end of long run. 


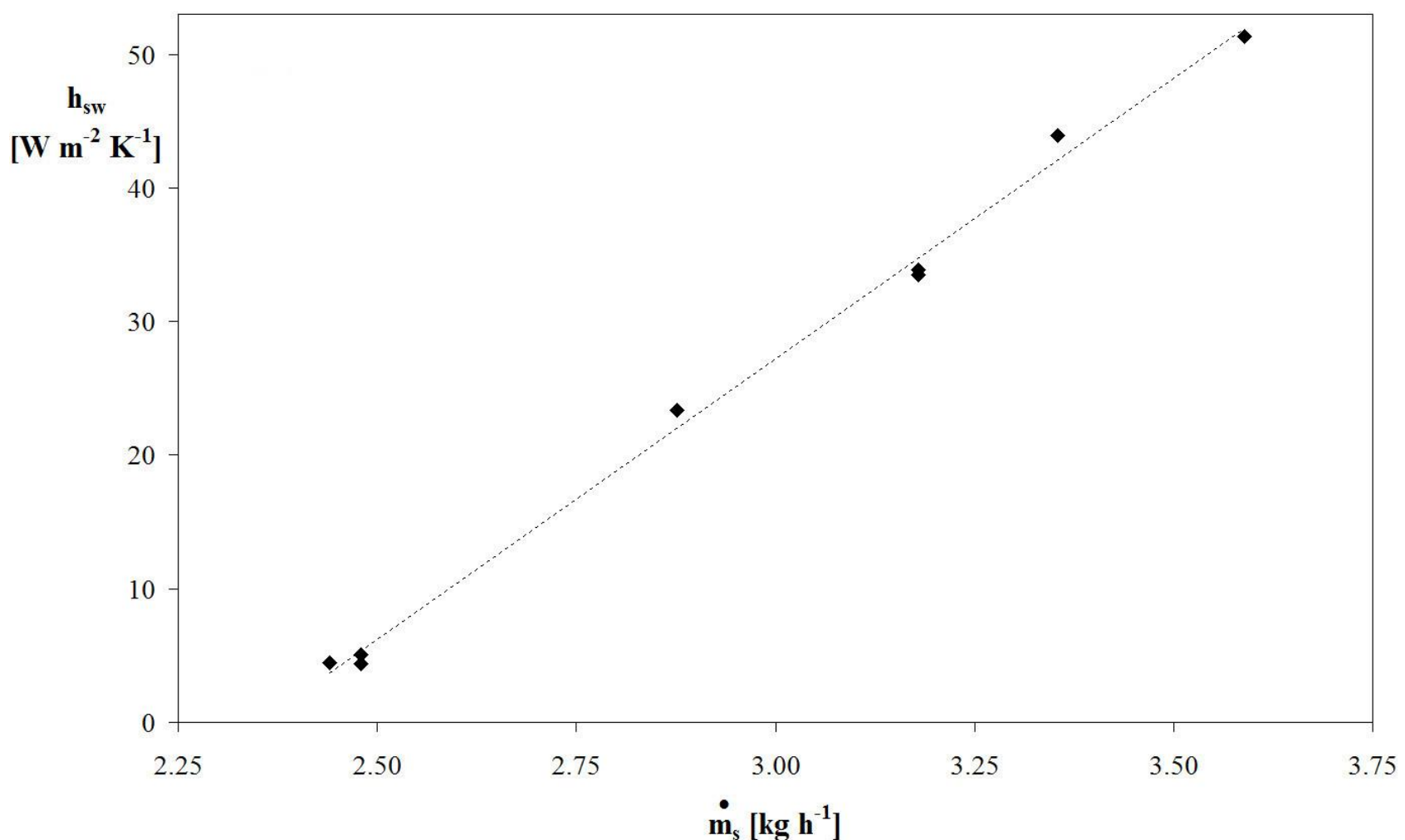

Figure 8. Wall to sand heat transfer coefficient as a function of sand mass flowrate at a constant rotational speed of $3 \mathrm{rpm}$. 


\section{TABLES}

Table 1. Wall to solid heat transfer coefficient obtained using different correlations.

\begin{tabular}{ll}
\hline Correlation & $\mathrm{h}_{\mathrm{sw}}\left[\mathrm{W} \mathrm{m}^{-2} \mathrm{~K}^{-1}\right]$ (order of magnitude) \\
\hline Wachters \& Kramers [8] & 44 \\
Dumont \& Belanger [9] & 30 \\
Tscheng \& Watkinson [10] & 185 \\
Imber \& Paschkis [11] & 0.1 \\
Lybaert [12] & 0.08 \\
\hline
\end{tabular}

Table 2. Variable parameters of the experimental device.

\begin{tabular}{ll}
\hline Parameter & Range \\
\hline Kiln inclination & 0 to 5 degrees \\
Kiln rotation speed & 0.5 to $12 \mathrm{rpm}$ \\
Screw rotation speed & 0.5 to $12 \mathrm{rpm}$ \\
Solid feed rate (with sand) & 1.5 to $7.5 \mathrm{~kg} \mathrm{~h}^{-1}$ \\
Bed Height & 0 to $33.5 \mathrm{~mm}$ \\
Internal kiln temperature & Up to $1000^{\circ} \mathrm{C}$ \\
Lifters & Removable \\
\hline
\end{tabular}

Table 3. Physical properties of the solid used in this study.

\begin{tabular}{ll}
\hline Material & Sand \\
Mean particle diameter & $0.54 \mathrm{~mm}$ \\
Bulk density & $1420 \mathrm{~kg} \mathrm{~m}^{-3}$ \\
Static angle of repose & 39 degrees \\
Thermal conductivity [10] & $0.268 \mathrm{~W} \mathrm{~m}^{-1} \mathrm{~K}^{-1}$ \\
Specific heat [12] & $835 \mathrm{~J} \mathrm{~kg}^{-1} \mathrm{~K}^{-1}$ \\
Emissivity [3] & 0.76 \\
\hline
\end{tabular}




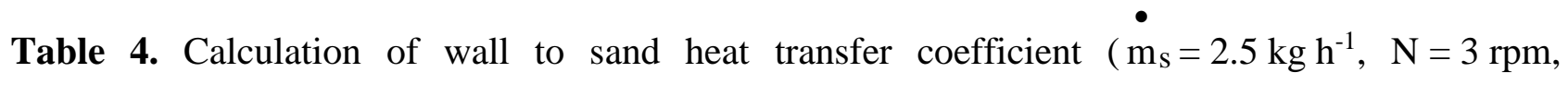
$\eta=23.5 \mathrm{~mm}$ and $\alpha=2^{\circ}$ ).

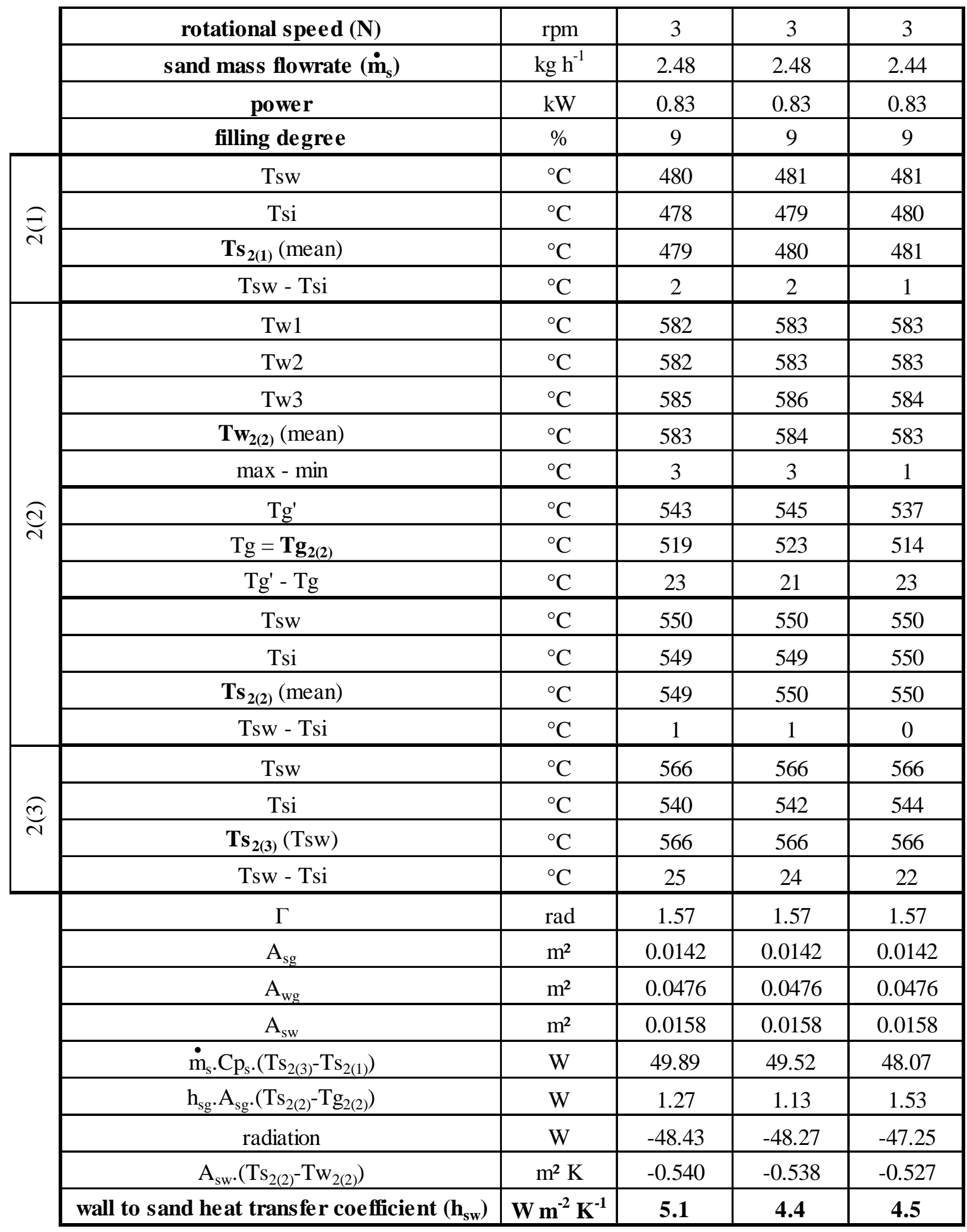


Table 5. Wall to sand heat transfer coefficient as a function of sand mass flowrate $\left(\mathrm{m}_{\mathrm{S}}\right)$ and rotational speed $(\mathrm{N}) ; \eta=23.5 \mathrm{~mm}$ and $\alpha=2^{\circ}$.

\begin{tabular}{|c|c|c|c|c|c|c|c|c|c|c|c|c|}
\hline $\mathbf{N}$ & $\mathrm{rpm}$ & 3 & 3 & 3 & 3 & 3 & 3 & 3 & 3 & 1 & 2 & 2 \\
\hline$\dot{\mathbf{m}}_{\mathbf{s}}$ & $\mathrm{kg} \mathrm{h}^{-1}$ & 2.48 & 2.48 & 2.44 & 2.88 & 3.18 & 3.18 & 3.35 & 3.59 & 2.47 & 2.49 & 2.50 \\
\hline $\mathbf{h}_{\mathbf{s w}}$ & $\mathbf{W ~ m}^{-\mathbf{2}} \mathbf{K}^{-\mathbf{1}}$ & $\mathbf{5 . 1}$ & $\mathbf{4 . 4}$ & $\mathbf{4 . 5}$ & $\mathbf{2 3 . 4}$ & $\mathbf{3 3 . 9}$ & $\mathbf{3 3 . 5}$ & $\mathbf{4 3 . 9}$ & $\mathbf{5 1 . 4}$ & $\mathbf{5 . 7}$ & $\mathbf{8 . 1}$ & $\mathbf{7 . 6}$ \\
\hline
\end{tabular}

